\title{
NOTES ON THE ELECTROLYTIC REDUCTION OF GLUCOSE.
}

\author{
By Alexander Findlay and Vernon Harcourt Williams.
}

\section{(A Paper read before The Faraday Society, Tuesday, March 22, I92 I, Professor Alfred W. Porter, F.R.S., President, in the Chair.)}

The possibility of reducing glucose electrolytically has attracted some attention in recent years, but the results obtained are somewhat conflicting. Thus O'Brien Gunn [D.R.P. I403 I 8 (I900)], states that glucose dissolved in sulphuric acid of $\mathrm{I}-3$ per cent. concentration, can be reduced electrolytically using graphite electrodes and a cell with a diaphragm, the current density at the cathode being $0^{\circ} 5 \mathrm{amp}$. per square decimetre. A yield of mannitol amounting to 98 per cent. of the theoretical is claimed to have been obtained.

W. Löb (Biochem. Zeitschr., I909, I7, I32; 21 , I02; Zeitschr. Elektrochem., I910, I6, I) on the other hand, failed to obtain this satisfactory result, and was led to conclude that both the anodic and cathodic electrolysis of glucose leads to an equilibrium between glucose, a pentose, formaldehyde, and lower carbohydrates, the cathodic reduction causing the equilibrium to shift in favour of the production of the lower compounds.

As the reduction of glucose to the corresponding hexahydric alcohol is in itself a process of importance, it seemed worth while to investigate the electrolytic process more fully, and, more especially, to study the effect on the reduction of variation of the temperature, current density, and current concentration. Although, as the result of our investigation, negative results, as regards the production of hexahydric alcohol, have been obtained, we desire to communicate some notes on our work which may prove of value in connection with this problem.

The method and apparatus employed were essentially those used by Tafel (Zeitschr. Physikal. Chem., I900, 34, 187), in his studies on electrolytic reduction. A closed cell was employed as cathode chamber and the volume of hydrogen evolved during electrolysis was compared with that evolved from a hydrogen voltameter placed in series with the electrolytic cell. The difference in the volume of hydrogen evolved in the two cells represents the amount of hydrogen used up in the reduction.

The glucose used was "extra pure" glucose supplied by British Drug Houses, Ltd. Examined polarimetrically it gave a rotation corresponding with a purity of 99.87 per cent.

In most of the experiments lead electrodes were employed, and as Tafel has shown that the presence of metal impurities has a very unfavourable influence on the cathodic reduction, care was taken to ensure the purity of the lead electrodes employed. The purity of the lead was tested by analysis of the surface layers and the results of analysis were also confirmed by a repetition of Tafel's experiments on the reduction of caffein. This control served also to show that our method of working was satisfactory. 


\section{NOTES ON ELECTROLYTIC REDUCTION OF GLUCOSE}

In the first series of experiments, carried out at the ordinary temperature, $14^{\circ}$ to $\mathrm{I} 7$, the current density employed was 0.16 amp. per 100 sq. $\mathrm{cm}$., and the solutions contained $\mathrm{I}, 3$, and ro per cent. of glucose in 3 per cent. sulphuric acid. In all cases the rate of absorption of hydrogen fell off rapidly, practically to zero, and the total amount absorbed corresponded with no more than about a 2 per cent. reduction of glucose. (See Table I.) In the following table, $t$ is the total time in minutes from the commencement of the experiment; $T$, the time in minutes from the commencement of the experiment to the middle of each period during which successive readings of the burette were made; $e$, the volume in c.c. of gas evolved in the electrolytic cell; $v$, the volume in c.c. of gas evolved in the voltameter; $\mathrm{E}$, the rate of evolution of gas in the electrolytic cell in c.c. per minute; $\mathrm{V}$, the rate of evolution of gas in the voltameter; $\mathrm{R}$, the rate of absorption of gas in c.c. per minute.

\section{TABLE I.}

Cathode liquid: I per cent., solution of glucose in 3 per cent. sulphuric acid. Current density : $0^{\circ} 16$ amperes per roo sq. $\mathrm{cm}$.

\begin{tabular}{|c|c|c|c|c|c|c|}
\hline$t$ & T. & e. & $v$ & E. & v. & R. \\
\hline $\begin{array}{r}0 \\
4 \\
8 \\
12 \\
16 \\
20 \\
24 \\
28 \\
38 \\
52 \\
62 \\
72\end{array}$ & $\begin{array}{r}2 \\
6 \\
10 \\
14 \\
18 \\
22 \\
26 \\
33 \\
45 \\
57 \\
67\end{array}$ & $\begin{array}{l}0 \\
0 \cdot 5 \\
I \cdot 25 \\
2 \cdot 1 \\
3 \cdot 1 \\
4 \cdot 15 \\
5 \cdot 15 \\
6 \cdot 2 \\
8 \cdot 9 \\
\text { I2.7 } \\
15 \cdot 5 \\
18 \cdot 25\end{array}$ & $\begin{array}{l}0 \\
1 \cdot 2 \\
2 \cdot 25 \\
3 \cdot 5 \\
4 \cdot 7 \\
5 \cdot 85 \\
7 \cdot 0 \\
8 \cdot 2 \\
I 1 \cdot 05 \\
15 \cdot 05 \\
17 \cdot 9 \\
20.8\end{array}$ & $\begin{array}{l}0.125 \\
0.187 \\
0.212 \\
0.250 \\
0.262 \\
0.250 \\
0.262 \\
0.270 \\
0.271 \\
0.280 \\
0.275\end{array}$ & $\begin{array}{l}0.300 \\
0.262 \\
0.312 \\
0.300 \\
0.287 \\
0.287 \\
0.300 \\
0.285 \\
0.285 \\
0.285 \\
0.290\end{array}$ & $\begin{array}{l}0.175 \\
0.075 \\
0.100 \\
0.50 \\
0.025 \\
0.037 \\
0.038 \\
0.015 \\
0.014 \\
0.005 \\
0.015\end{array}$ \\
\hline
\end{tabular}

The total volume of hydrogen absorbed in the above experiment over the period of 72 minutes was only $1 \cdot 42$ c.c. at N.T.P.

Similar results were obtained on commencing the electrolysis with a peroxidised lead cathode, and also when the sulphuric acid was replaced by sodium bisulphate as electrolyte.

Influence of Temperature.-On carrying out the electrolysis at a temperature of about $44^{\circ}$, no better results were obtained. The influence of temperature was found to be practically inappreciable; if anything, the hydrogen absorption was diminished.

Graphite Electrodes.-On using electrodes of gas carbon or of Acheson graphite the results were similar to those obtained with a lead electrode.

Current Density and Current Consentration.-In general, reduction of the cathodic current density is accompanied by a slight increase in the efficiency of electrolytic reduction, but although we carried out an experiment with a current density somewhat lower than that previously employed (0.102 instead of $0.16 \mathrm{amp}$. $/ \mathrm{sq}$. dcm.), no appreciable improvement was observed. It has, however, been shown by Tafel (loc. cit.), that current concentration (current per unit volume of solution), has a greater influence than current density. Experiments were therefore carried out in which the current concentration was varied between the limits of 0.04 
and 0.444 amps. per 100 c.c. The results obtained showed that with increase of current concentration, the absorption of hydrogen also increases but, as in previous experiments, falls off rapidly with time.

During the progress of these experiments it was observed that the cathode solution, after electrolysis, possessed a sharp aldehydic odour, and the cathode was found to be coated with a film of slimy appearance. 'This film was soluble in alcohol. As it was thought that the production of this film might be the cause of the rapid falling off of the volume of hydrogen absorbed by the depolariser, experiments were carried out in which the same solution was subjected to repeated electrolysis, the cathode, after each run, being treated with boiling alcohol to remove the film produced. After each treatment of the cathode it was found that a further absorption of hydrogen took place, but that this absorption again rapidly fell off to zero. Using a current concentration of 0.444 amps. per 100 c.c., and a cathode solution of 20 per cent. glucose in 5 per cent. sulphuric acid, the following successive absorptions of hydrogen were realised: $28 \cdot 5,8 \cdot 1,32 \cdot 2,52 \cdot 8,30^{\cdot 2}, 24 \cdot x$, and 23.5 c.c. The total absorption amounted therefore to $199^{\circ} 4$ c.c., or $40^{\circ} \mathrm{I}$ per cent. of the theoretical amount. During these experiments, which extended over several hours, a considerable loss of glucose took place by diffusion from the cathode cell. In the most favourable case, where the highest current was employed, the loss amounted to nearly 30 per cent.; where lower currents were employed and the duration of the electrolysis was therefore greater, the loss by diffusion was of course also greater. Attempts to diminsh diffusion by use of a membrane of copper ferrocyanide deposited in the wall of the porous cathode cell, were not successful.

Since the foregoing experiments seemed to indicate that a considerable proportion of the glucose had been reduced, an attempt was made to isolate the supposed product of reduction, the hexahydric alcohol. The solution was neutralised with chalk to remove sulphuric acid, and was then evaporated on the water bath. The syrupy liquid was dissolved in concentrated hydrochloric acid and the acid solution shaken with benzaldehyde and allowed to stand for several days. By this means, mannitol or sorbitol, if present, can be precipitated as a condensation product with benzaldehyde (Meunier, Compt. rend., r888, 107, 9ro). No such compound, however, was obtained, and we are therefore driven to conclude that no appreciable amount of hexahydric alcohol was produced in our electrolytic experiments.

On examining the alcoholic washings from the cathode, a lead salt was isolated which, on analysis, was found to be lead formate. Formic acid was also found in the cathode solution after electrolysis. The production of this acid in the electrolytic reduction of glucose is mentioned by Löb (Zeitschr. Elektrochem., I9I0, 16, I), who states that glucose decomposes into formic acid and a pentose. The presence of pentose in the solution we detected by the furfuraldehyde test.

Further evidence of the production of formic acid was obtained from an analysis of the gas evolved at the cathode during electrolysis. This gas was found to be not pure hydrogen but to contain about 4 per cent. of carbon monoxide, produced, presumably, by a decomposition of formic acid. The percentage of carbon monoxide varied somewhat during electrolysis, being greater during the earlier than during the later stages of the electrolysis. Although the destructive reduction of glucose with production of formic acid and a pentose does not appear to take place to a very large extent, the formation of these compounds may play an important 


\section{$45^{6}$ NOTES ON ELECTROLYTIC REDUCTION OF GLUCOSE}

part in the process of electrolytic reduction if; as seems probable, it is the formic acid which leads to the formation of the film on the cathode with consequent diminution or prevention of further reduction.

As a result of our experiments, which are in harmony with the results obtained by Lob, we are forced to conclude that, contrary to the claims of O'Brien Gunn, no hexahydric alcohol is produced in the electrolytic reduction of glucose.

Chemistry Department, University of Aberdeen. 